\title{
Relationships of alcohol intake with biological health outcomes in an African population in transition: the Transition and Health during Urbanisation in South Africa (THUSA) study
}

\author{
a Gopane RE, MSc ${ }^{\mathrm{b}}$ Pisa PT, PhD ${ }^{\mathrm{b}}$ Vorster HH, DSc ${ }^{\mathrm{b}}$ Kruger A, PhD ${ }^{\mathrm{c}}$ Margetts BM, PhD \\ ${ }^{a}$ Department of Biological Sciences, North-West University, Mafikeng Campus, Mmabatho 2735, South Africa ${ }^{\circ}$ Centre of Excellence for Nutrition, \\ North-West University, Potchefstroom 2520, South Africa ${ }^{c}$ Institute of Human Nutrition, University of Southampton, Southampton, UK \\ Correspondence to: Dr PT Pisa; email:20369190@nwu.ac.za/pedropisa2005@yahoo.com \\ Keywords: alcohol; Africans; nutrition transition; iron status; ferritin
}

\section{Abstract}

Objective: Because present recommendations on alcohol intake are based mainly on evidence of beneficial effects in populations of developed countries, this study examines biological effects of alcohol consumption in an African population in transition to assess whether these recommendations are also valid for Africans.

Design: A cross-sectional, comparative, population-based study.

Setting: Thirty-seven randomly selected sites in the North West province of South Africa, representing both rural and urban areas.

Subjects: A total of 1854 apparently healthy men and women older than 15 years volunteered to participate. Complete data of 1757 participants were available for analysis. Pregnant and lactating women as well as subjects taking any form of chronic medication, those with oral temperatures above $37^{\circ} \mathrm{C}$ and those who were inebriated were excluded.

Outcome measures: A validated, quantitative food frequency questionnaire was used to measure dietary intake, including alcoholic beverages, expressed as absolute alcohol in grams per day. Anthropometric measurements and blood pressure were taken in triplicate using standardised equipment and procedures. Fasting blood samples were used to determine biochemical variables related to nutritional status and health. Serum gamma glutamyl transferase was used to examine the reliability of reported alcohol intake. The SPSS package was used to relate alcohol intake to blood pressure and biochemical variables, controlling for age, body mass index and blood glucose. Data from men and women, as well as drinkers and non-drinkers, were analysed separately and compared.

Results: In total, $61.5 \%$ of the men and $25.2 \%$ of the women reported that they consumed alcoholic beverages. The mean alcohol intake of men ( $30.2 \pm 47.8 \mathrm{~g} /$ day) exceeded the recommend value of $21 \mathrm{~g} /$ day. The women had a mean intake of $11.4 \pm 18.8 \mathrm{~g} / \mathrm{day}$, falling within the 12 to $15 \mathrm{~g} /$ day recommendation. Older drinkers (> 40 years) and those infected with HIV drank more. The level of urbanisation had little effect on amounts consumed. Drinkers had significantly higher HDL cholesterol (HDL-C), serum triglycerides, blood pressure and iron status variables than non-drinkers. These effects represent some beneficial but mostly detrimental consequences of alcohol consumption. When serum ferritin was used to classify subjects into those in negative iron balance $(<12 \mu \mathrm{g} / \mathrm{L})$, 'normal' iron balance $(12-150 \mu \mathrm{g} / \mathrm{L})$ and positive iron balance ( $>150 \mu \mathrm{g} / \mathrm{L}$ ), it became evident that alcohol intake almost doubled the proportion of subjects in positive iron balance (in men from 25 to $46 \%$; in women from 11 to $23 \%$ ).

Conclusion: Although the beneficial effect of alcohol consumption on HDL-C was seen in this population, the effects on iron status and balance are of concern and should be researched in more detail.

(P) Peer reviewed. (Submitted: 2008-08-12, Accepted: 2009-08-10). ๑ SAJCN

S Afr J Clin Nutr 2010;23(3)(Supplement 1):S16-S21

\section{Introduction}

The food-based dietary guidelines of many countries, ${ }^{1}$ including South Africa, ${ }^{2}$ recommend to the public that if alcohol is consumed, it should be in moderation, limited or consumed sensibly., ${ }^{1,2}$ In those guidelines that specify quantities, sensible or moderate consumption is usually not more than two drinks for men and one drink for women per day, a drink being equal to about $15 \mathrm{~g}$ of pure alcohol. This recommendation is based on the reality that there will always be alcohol consumers in any population and that moderate, limited or sensible consumption has been proven to have specific health benefits. The South African guideline, "If you drink alcohol, drink sensibly", is accompanied by an excellent support paper ${ }^{2}$ that provides the evidence for both positive and negative social and physical health effects of alcohol consumption. This paper ${ }^{2}$ and others ${ }^{3}$ describe the patterns of alcohol consumption in South Africa, but the evidence of the physical health benefits of moderate consumption mainly comes from studies in other countries because of a lack of South African data on possible beneficial effects. In addition to the well-known cardio-protective effects of moderate consumption, primarily mediated through increased HDL cholesterol (HDL-C) and haemostasis, ${ }^{2}$ there are studies that claim benefits on iron $(\mathrm{Fe})$ status. ${ }^{4,5}$

A recent publication ${ }^{4}$ of the Dikgale study in the Limpopo province of South Africa concluded that "traditional beer consumption seemed to prevent iron deficiency in those at risk of developing such a deficiency, but appeared to precipitate iron overload in those at risk 
of developing iron overload". This potential "beneficial" effect of alcohol consumption on serum ferritin (S-Ft) levels and iron status has also been observed in other African, ${ }^{5}$ elderly, ${ }^{6,7}$ Danish $^{8}$ and Australian ${ }^{9}$ populations. However, the relationship between alcohol consumption and ferritin (Ft) levels is also a known consequence of liver damage in chronic alcoholics. ${ }^{10,11}$ The mechanisms through which these effects are mediated are unclear. ${ }^{12-14}$ In this study we therefore analysed the THUSA data to examine the relationships between alcohol consumption and both 'positive' and 'negative' biological outcomes in an African population in transition ${ }^{15}$ to gain more information to either support or warn about the present alcohol guideline ${ }^{2}$ to South African consumers. The term "transition" is used to describe a population that is migrating from rural to urban areas, and in the process is exposed to modern lifestyles and changing food environments, with resultant changes in diets.

\section{Methods}

\section{Study design, subject selection and organisational procedures}

The THUSA study (Transition and Health during Urbanisation in South Africa) was conducted from 1996 to 1998 in the North West Province of South Africa. ${ }^{15}$ It was a cross-sectional comparative study in which a community-based sample of 1854 apparently healthy African volunteers ( 15 years and older) were recruited from 37 randomly selected sites, using a statistical model that ensured a representative sample from five levels of urbanisation: deep rural, commercial farms, informal settlements, "middle class" urban and "upper class' urban. ${ }^{15}$ Pregnant and lactating women, individuals taking chronic medication, those with oral temperatures above $37^{\circ} \mathrm{C}$ and inebriated volunteers were excluded. Permission to conduct the study in specific areas with advice on recruitment procedures was obtained from the North West Department of Health, tribal chiefs, community leaders, headmasters of high schools, employees and mayors. The study was approved by the Ethics Committee of North-West University (Ethics number: 4M5-95) and all participating subjects signed an informed consent form. Subjects fasted (10-12 hours) for the baseline blood sample and other measurements. They received lunch after completion of the glucose tolerance test. All subjects received feedback regarding their blood pressure, fasting glucose levels and haemoglobin values. Where necessary, subjects were referred to their nearest health facility for further diagnosis and treatment. Subjects' travelling expenses were paid. Of the 1854 participants, complete data for 1757 were available for analysis.

\section{Questionnaires}

The questionnaires used were designed based on or adapted from available and appropriate questionnaires for this study population, and were validated with appropriate methods. ${ }^{15,16}$ Questionnaires were issued during individual interviews conducted by the researchers and specially trained African field workers in the language of the subjects' choice. The questionnaires were available in Setswana, English or Afrikaans. The fieldworkers were trained to record dietary intake using a quantitative food frequency questionnaire (QFFQ) during individual interviews with the subjects. As described by Macintyre, ${ }^{16}$ pictures of a variety of foods were used to quantify portion sizes.

The demographic, health and lifestyle questionnaire included questions on type of housing, access to electricity, water source, sanitation, personal and household income, health history (also of close family members), number and ages of people living in the house, ownership of property, education level, and smoking and drinking habits. As mentioned above, dietary intake was measured with a QFFQ developed after a pilot study in which all foods consumed by this population were assessed by comparisons with weighed records. Nutrient intakes were analysed by means of the Medical Research Council (MRC) programme based on the South African Food Composition Tables, ${ }^{17}$ including grams of alcohol consumed per day.

\section{Anthropometric measurements}

An anthropometrist and specially trained postgraduate students (trained by a level 1 anthropometrist) measured height (stature), weight, seven skinfold thicknesses and body circumferences of subjects in their underwear with calibrated instruments (Precision Health Scale, A \& D Company, Japan; Invicta Stadiometer, IP 1465, UK; Holtain ${ }^{\circledR}$ unstretchable metal tape; John Bull ${ }^{\circledR}$ callipers). Skinfold measurements were taken in triplicate.

\section{Clinical examinations}

Two registered nursing sisters specially trained to recognise symptoms and signs of undernutrition examined the subjects. Oral temperatures were taken and blood pressure recorded, also in triplicate using a sphygmomanometer $\left(T y \cos ^{\circledR}\right)$ with adjustable cuffs of different sizes.

\section{Glucose tolerance test}

After a fasting blood sample was taken, a two-hour glucose tolerance test (GTT) commenced during which subjects took a $75 \mathrm{~g}$ glucose load (Alpha ${ }^{\circledR}$ glucose powder, Allied Pharmaceuticals) dissolved in $250 \mathrm{ml}$ water. During blood collection, $5 \mathrm{ml}$ of venous blood samples were collected at 15, 30, 60, 90 and 120 minutes after the glucose load in fluorodised tubes. Blood samples were allowed to clot, immediately centrifuged, aliqoutted into two Eppendorff tubes, and stored as described in the next paragraph.

\section{Blood, serum, plasma, urine and cell samples}

Blood was drawn from the vena cephalica using a sterile butterfly infusion set (Johnson \& Johnson, $21 \mathrm{G}, 19 \mathrm{~mm}$ ) and syringes. For preparation of serum, $5 \mathrm{ml}$ blood was allowed to clot in glass tubes at room temperature, centrifuged at $3000 \mathrm{rpm}$ for 15 minutes (Universal 16RTM, Hettich, with cooling facilities), and transferred into $30 \times 1 \mathrm{ml}$ Eppendorff tubes. Citrated blood was prepared by drawing $4.5 \mathrm{ml}$ blood into a syringe containing $0.5 \mathrm{ml} 1 \mathrm{~mol} / \mathrm{L}$ citrate (pH 4.5-4.8). These samples were centrifuged for 10 minutes at $3000 \mathrm{rpm}$ in plastic siliconised tubes and the plasma stored in $5 \times 1 \mathrm{ml}$ Eppendorff tubes. Haematocrit (centrifuge method) and haemoglobin levels (Boehringer Mannheim) were measured in the field on unclotted blood. All serum, plasma and separated blood cells samples were immediately stored at $-18{ }^{\circ} \mathrm{C}$ to $-20{ }^{\circ} \mathrm{C}$ in the field for two to four days and afterwards at $-84^{\circ} \mathrm{C}$ in the laboratory.

\section{Biochemical analyses}

Serum proteins, minerals, electrolytes, glucose, lipids and enzymes were determined with the DAX system (discrete analyser Technicon DAX 48) in the Department of Chemical Pathology, University of Pretoria. Serum vitamin $A$ and $E$ as well as iron, ferritin, iron binding capacity and transferrin were determined in the MRC laboratory of the National Research Programme for Nutrition Intervention at Tygerberg, using immunological, colorimetric and high-performance liquid chromatography methods. Fibrinogen was measured in citrated plasma with the method of Clauss using the AC-L200 (Milan, Italy) system and the international fibrinogen standard (National Institute for Biological Standards and control [code 89/644], Hertfordshire, UK). 


\section{Statistical analyses}

Data were analysed with the Statistical Package for Social Sciences (SPSS version 16). Means, medians, standard deviations, standard errors and $95 \%$ confidence intervals were calculated. Data that were not normally distributed were logarithmically transformed and non-parametric tests were used to test for significant differences between groups and effects of urbanisation. Univariate analysis of variance (ANOVA), the post hoc test of least significant differences (LSD), multivariate regression analysis, stepwise regression methods and Spearman rank-order correlations with adjustments for confounding factors were used to examine the influence of alcohol consumption on biological (health) variables. For this study, drinkers and non-drinkers and men and women were analysed separately. To assess the relationship between alcohol and serum ferritin, men and women were grouped into those with negative iron balance (Group 1: serum ferritin below $12 \mu \mathrm{g} / \mathrm{L}$ [according to Kasdan, ${ }^{18}$ it can be S-Ft $<25 \mu \mathrm{g} / \mathrm{L}]$ ), 'normal' iron balance (Group 2: serum ferritin between 12 and $150 \mu \mathrm{g} / \mathrm{L}$ [according to Kasdan,18 it can be S-Ft 100 $+/-60 \mu \mathrm{g} / \mathrm{L}]$ ) and positive iron balance (Group 3: serum ferritin above $150 \mu \mathrm{g} / \mathrm{L}$; above $150 \mu \mathrm{g} / \mathrm{L}$ may indicate an Fe overload). ${ }^{18}$ These cut-off points were used as they are the clinical cut-off points recommended by a standard dietetic practice. ${ }^{18}$

Data collection for the THUSA study was done in 1996 and 1998. To test whether the two sets of data could be combined, the total reported energy intake of women in the 1996 and 1998 data sets were compared. The mean intake of the 1996 group was $7975 \mathrm{~kJ}$ and of the 1998 group $7997 \mathrm{~kJ}$, so the two sets of data were combined.

\section{Results}

The mean daily alcohol consumption of the THUSA participants are shown in Table I, while the mean intake of subjects in different levels of urbanisation are shown in Table II. Proportionally, more men than women consumed alcohol (62 vs $25 \%$ respectively). The mean intake of men was more than double that of women (30.2 vs $11.4 \mathrm{~g} /$ day respectively). Men and women older than 40 years had a higher mean intake than those younger than 40 years.

Men from the urban middle class level (Table II) constituted the highest proportion of drinkers (73\%) and also had the highest mean intake of alcohol (33.7 g/day). Women living on farms had the highest mean intake ( $15.2 \mathrm{~g} /$ day) but a larger proportion of women in informal housing areas reported that they consumed alcoholic beverages (35\%).

Table III shows that HIV-infected subjects had a slightly higher mean intake of alcohol than non-infected drinkers. The percentage of drinkers who were HIV infected was similar in men and women (13.5 and $13.7 \%$ respectively). It is not shown in Table III, but in the total sample of drinkers and non-drinkers, $13 \%$ of the men and $11.6 \%$ of the women were infected. ${ }^{15}$

Table IV compares the means of variables suspected of being influenced by alcohol consumption between drinkers and nondrinkers. The mean age of the male drinkers was significantly higher than that of the non-drinkers, and therefore all correlations were adjusted for age. In both men and women serum HDL-C, but also serum triglycerides, was significantly higher in drinkers. Blood pressure, serum iron (but not haemoglobin) as well as serum ferritin levels were significantly higher in male and female drinkers. Total iron binding capacity (TIBC) differed significantly in drinking and non-drinking men as did transferrin saturation (Tf-sat) in both men
Table I: Reported mean daily alcohol consumption of the THUSA participants

\begin{tabular}{|c|c|c|c|c|}
\hline \multicolumn{2}{|c|}{ Subject group } & n (\%) & Mean $(\mathrm{g} / \text { day })^{*}$ & SD \\
\hline \multicolumn{2}{|l|}{ Men: drinkers } & $456(61.5)$ & 30.2 & 47.8 \\
\hline \multicolumn{2}{|l|}{ Men: non-drinkers } & $286(38.5)$ & - & - \\
\hline \multicolumn{2}{|l|}{ Women: drinkers } & 256 (25.2) & 11.4 & 18.8 \\
\hline \multicolumn{2}{|c|}{ Women: non-drinkers } & 759 (74.8) & - & - \\
\hline \multirow[t]{2}{*}{ Men: drinkers } & $<40$ years & $255(55.9)$ & 25.6 & 40.7 \\
\hline & $\geq 40$ years & $201(44.1)$ & 36.0 & 55.1 \\
\hline \multirow[t]{2}{*}{ Women: drinkers } & $<40$ years & $134(52.3)$ & 10.8 & 20.7 \\
\hline & $\geq 40$ years & $122(47.7)$ & 12.0 & 16.5 \\
\hline
\end{tabular}

* Grams of absolute alcohol calculated from reported intake of alcoholic beverages using the South African Food Composition Tables ${ }^{17} \mathrm{SD}=$ standard deviation

Table II: Mean daily alcohol intake of male and female drinkers at different levels of urbanisation

\begin{tabular}{|l|c|c|c|c|}
\hline \multicolumn{1}{|c|}{ Subject group } & $n$ & $\%^{*}$ & Mean (g/day) & SD \\
\hline Men: drinkers (all ages) & & & & \\
\hline Rural & 100 & 52 & 31.5 & 47.7 \\
\hline Farms & 58 & 54 & 20.5 & 21.1 \\
\hline Informal settlements & 88 & 69 & 30.8 & 49.8 \\
\hline Urban middle class & 168 & 73 & 33.7 & 56.9 \\
\hline Urban upper class & 42 & 49 & 25.0 & 24.6 \\
\hline Total & 456 & 61 & 30.2 & 47.8 \\
\hline Women: drinkers (all ages) & & & & \\
\hline Rural & 55 & 19 & 12.1 & 14.2 \\
\hline Farms & 43 & 29 & 15.2 & 19.3 \\
\hline Informal settlements & 61 & 35 & 10.9 & 20.8 \\
Urban middle class & 75 & 26 & 11.6 & 21.6 \\
Urban upper class & 22 & 21 & 2.8 & 6.2 \\
\hline Total & 256 & 25 & 11.4 & 18.8 \\
\hline
\end{tabular}

* Percentage of drinkers of total participants in each urbanisation group $\mathrm{SD}=$ standard deviation

Table III: Mean daily alcohol consumption of HIV-infected and non-infected subjects who reported that they drank

\begin{tabular}{|l|c|c|c|c|c|}
\hline \multicolumn{2}{|c|}{ Subject group } & $\mathrm{n}$ & $\%^{*}$ & Mean (g/day) & SD \\
\hline Men: & HIV-infected & 62 & 13.5 & 36.2 & 67.7 \\
& Non-infected & 396 & 86.5 & 29.1 & 43.8 \\
\hline \multirow{2}{*}{ Women: } & HIV-infected & 35 & 13.7 & 13.0 & 15.3 \\
\cline { 2 - 6 } & Non-infected & 221 & 86.3 & 11.1 & 19.3 \\
\hline
\end{tabular}

* Percentage of drinkers $\mathrm{SD}=$ standard deviation

and women. The mean reported dietary intake of iron of drinkers and non-drinkers did not differ significantly.

Table $\mathrm{V}$ shows that when controlling for the factors known to influence gamma glutamyl transferase (GGT), namely age, BMI and fasting blood glucose, the correlation between GGT and reported alcohol intake in men was not significant. In women, the correlation was highly significant $(r=+0.233 ; p=0.0001)$. The same table shows that when controlling for age and BMl, factors known to influence HDL-C had a significant positive correlation with alcohol consumption in both men and women. In women there was an even higher correlation with serum triglycerides and also a significant correlation with serum total cholesterol. The correlation between alcohol consumption and blood pressure disappeared in both men and women when controlling for age and BMl. The correlations between alcohol consumption and iron status variables are also shown in Table $\mathrm{V}$, and were significant in men but not in women, except for serum ferritin. There was a significant correlation 
Table IV: Comparison of biochemical, physiological and dietary data of drinkers and non-drinkers

\begin{tabular}{|c|c|c|c|c|c|c|c|c|}
\hline \multirow[t]{3}{*}{ Variable } & \multicolumn{4}{|c|}{ Men } & \multicolumn{4}{|c|}{ Women } \\
\hline & \multicolumn{2}{|c|}{ Drinkers } & \multicolumn{2}{|c|}{ Non-drinkers } & \multicolumn{2}{|c|}{ Drinkers } & \multicolumn{2}{|c|}{ Non-drinkers } \\
\hline & Mean & SD & Mean & SD & Mean & SD & Mean & SD \\
\hline Age (years) & $39.2^{\star}$ & 14.5 & 33.9 & 16.2 & 39.2 & 13.1 & 37.3 & 14.5 \\
\hline Body mass index (BMI) (kg/m²) & 21.0 & 3.5 & 21.2 & 4.1 & 26.8 & 7.2 & 27.0 & 6.7 \\
\hline Total serum cholesterol (mmol/L) & 4.04 & 1.02 & 3.91 & 0.94 & 4.24 & 1.00 & 4.24 & 1.11 \\
\hline $\mathrm{HDL}-\mathrm{C}(\mathrm{mmol} / \mathrm{L})$ & $1.30^{\star}$ & 0.44 & 1.07 & 0.30 & $1.23^{\#}$ & 0.37 & 1.12 & 0.30 \\
\hline Serum triglycerides (mmol/L) & $1.24^{*}$ & 0.88 & 1.10 & 0.61 & $1.40^{\#}$ & 1.01 & 1.09 & 0.58 \\
\hline \multicolumn{9}{|l|}{ Blood pressure (mmHg) } \\
\hline Systolic & $128^{*}$ & 17 & 123 & 15 & $132^{\#}$ & 25 & 126 & 20 \\
\hline Diastolic & $78^{\star}$ & 12 & 75 & 11 & $82^{\#}$ & 15 & 77 & 13 \\
\hline Haemoglobin (g/dL) & 13.5 & 2.2 & 13.5 & 2.0 & 12.4 & 2.1 & 12.1 & 2.1 \\
\hline Serum iron (mmol/L) & $20.4^{\star}$ & 9.1 & 16.5 & 7.4 & $16.6^{\#}$ & 7.8 & 14.8 & 7.7 \\
\hline Serum TIBC (mmol/L) & $64.1^{*}$ & 11.6 & 66.4 & 15.4 & 69.2 & 12.2 & 69.4 & 14.3 \\
\hline Transferrin saturation (\%) & $32.4^{*}$ & 14.6 & 26.0 & 13.0 & $24.8^{\#}$ & 12.4 & 22.0 & 12.0 \\
\hline Serum ferritin $(\mu \mathrm{g} / \mathrm{L})$ & $243^{*}$ & 345 & 141 & 252 & $115^{\#}$ & 176 & 74 & 145 \\
\hline Dietary intake of iron (mg) & 9.3 & 4.4 & 9.0 & 4.4 & 8.9 & 4.2 & 8.4 & 4.1 \\
\hline
\end{tabular}

* Significant difference between male drinkers and non-drinkers (ANOVA; $p \leq 0.02)$ \# Significant difference between female drinkers and non-drinkers (ANOVA; $p \leq 0.02) \quad S D=$ standard deviation

between alcohol consumption and ferritin in women only. In men, haemoglobin, serum iron and transferrin saturation had low but significant correlations with alcohol intake.

Table VI compares the mean values of iron status variables in male drinkers and non-drinkers divided into three groups of 'iron balance'. For this purpose, serum ferritins of $12 \mu \mathrm{g} / \mathrm{L}$ and $150 \mu \mathrm{g} / \mathrm{L}$ were used to distinguish between those in negative (Group 1) and positive (Group 3) balance.$^{18}$ As expected, the mean ages of those in positive balance were higher than those in normal or negative balance because of the known influence of age (significant in the drinkers).

The mean alcohol intake of the male drinkers in negative balance (Group 1) was $6.6 \mathrm{~g} /$ day, compared to $26.8 \mathrm{~g} /$ day of those in balance (Group 2) and the $34.8 \mathrm{~g} /$ day of those in positive balance (Group 3). These striking differences were, however, only significant on a $10 \%$ level $(p \leq 0.094)$. In the male drinkers, the significant differences between the three groups of serum iron (S-Fe) and blood haemoglobin $(\mathrm{Hb})$ evident in the non-drinkers were not observed. In the non-drinkers, $6 \%$ of the men were, according to criteria used here, in negative iron balance and $25 \%$ in positive balance (Table $\mathrm{VI})$. In the drinkers, only $2 \%$ were in negative balance but $46 \%$ in positive balance.

Table VII shows similar data for women, with the difference that in female drinkers the lowest mean alcohol intake was observed in Group $2(7.7+/-11.7 \mathrm{~g} /$ day, thought to be in iron balance (S-Ft levels between 12 and $150 \mu \mathrm{g} / \mathrm{L})$. Significant differences between groups for serum iron and blood haemoglobin were observed in both drinkers and non-drinkers. In female drinkers the proportion in negative balance was $14 \%$ and in positive balance $23 \%$, compared to the 17 and $11 \%$ of non-drinkers.

\section{Discussion}

\section{Limitation of reported intake}

The first issue to address is the reliability of the reported alcohol intake, because how much and what one drinks may be a
Table V: Significant correlations between reported alcohol intake and other variables* (drinkers only)

\begin{tabular}{|l|c|c|c|c|}
\multicolumn{1}{|c|}{ Variable } & \multicolumn{2}{c|}{ Men } & \multicolumn{2}{c|}{ Women } \\
\hline Serum GGT & R & p & $\mathbf{R}$ & $\mathbf{p}$ \\
\hline $\begin{array}{l}\text { Serum total } \\
\text { cholesterol }\end{array}$ & - & NS & 0.233 & 0.0001 \\
\hline HDL-C & NS & 0.145 & 0.029 \\
\hline Triglycerides & -141 & 0.005 & 0.168 & 0.011 \\
\hline Haemoglobin (g/dL) & 0.112 & 0.026 & & NS \\
\hline Serum iron & 0.110 & 0.030 & & NS \\
\hline \% saturation & 0.102 & 0.044 & & NS \\
\hline Ferritin & & NS & 0.152 & 0.021 \\
\hline
\end{tabular}

* Controlled for age and BMI

\# Controlled for age, BMl and fasting blood glucose

Significant difference when $\mathrm{p}<0.05$

$r=$ correlation coefficient (Spearman rank order)

sensitive question. Intake was assessed in two questionnaires: the demographic, health and lifestyle questionnaire ${ }^{15}$ to get an indication of drinking patterns and the validated $Q F F Q^{16}$ to measure habitual intake of specific alcoholic beverages. The latter was used to calculate absolute alcohol intake per day. GGT is often used in epidemiological studies $^{19}$ as a proxy for alcohol intake. This liver enzyme detected in serum is, however, non-specific and may also be influenced by other factors, such as diabetes. Although the population sample was recruited as apparently healthy, some subjects were diagnosed with diabetes ${ }^{15}$ and therefore blood glucose as well as age and BMI were controlled for to determine the relationship between reported alcohol intake and GGT. In women this relationship was highly significant but not in men, suggesting that women may have been more accurate and 'honest' in their estimates of alcohol consumed. Nonetheless, the expected significant correlations between reported intake 
Table Vl: Comparison of low, normal and high ferritin groups of male drinkers and non-drinkers

\begin{tabular}{|c|c|c|c|c|c|c|c|}
\hline \multicolumn{2}{|c|}{ Variable } & \multicolumn{3}{|c|}{ Drinkers } & \multicolumn{3}{|c|}{ Non-drinkers } \\
\hline & & 1 & 2 & 3 & 1 & 2 & 3 \\
\hline Number & & 7 & 229 & 203 & 16 & 199 & 72 \\
\hline Proportion (\%) & & 2 & 52 & 46 & 6 & 69 & 25 \\
\hline Age (years) & Mean & 22.6 & 34.0 & $45.8^{\#}$ & 25.8 & 31.0 & 44.4 \\
\hline & SD & 6.4 & 13.3 & 13.4 & 14.6 & 16.0 & 12.3 \\
\hline Alcohol intake & Mean & 6.6 & 26.8 & 34.8 & & & \\
\hline (g/day) & SD & 7.0 & 44.1 & 52.3 & & & \\
\hline Serum ferritin & Mean & 6 & 75 & $440^{\#}$ & 6 & 64 & $384^{\dagger}$ \\
\hline$(\mu \mathrm{g} / \mathrm{L})$ & SD & 3 & 37 & 429 & 3 & 38 & 415 \\
\hline Serum iron & Mean & 12.8 & 19.8 & 21.3 & 9.6 & 16.6 & $17.6^{\dagger}$ \\
\hline$(\mu \mathrm{g} / \mathrm{L})$ & SD & 5.3 & 8.9 & 9.3 & 10.2 & 6.7 & 7.6 \\
\hline Haemoglobin & Mean & 12.8 & 13.7 & 13.3 & 11.5 & 13.6 & $13.4^{\dagger}$ \\
\hline$(\mathrm{g} / \mathrm{dL})$ & SD & 1.4 & 2.4 & 1.9 & 2.5 & 1.9 & 2.0 \\
\hline
\end{tabular}

Group 1: Serum ferritin levels below $12 \mu \mathrm{g} / \mathrm{L}$

Group 2: Serum ferritin levels between 12 and $150 \mu \mathrm{g} / \mathrm{L}$

Group 3: Serum ferritin levels above $150 \mu \mathrm{g} / \mathrm{L}$

\# Significant differences within the drinkers groups (ANOVA; $p \leq 0.001$ )

$\dagger$ Significant differences within the non-drinkers groups (ANOVA; $p \leq 0.001$ )

$\mathrm{SD}=$ standard deviation

Table VII: Comparison of low, normal and high ferritin groups of female drinkers and non-drinkers

\begin{tabular}{|c|c|c|c|c|c|c|c|}
\hline \multicolumn{2}{|c|}{ Variable } & \multicolumn{3}{|c|}{ Drinkers } & \multicolumn{3}{|c|}{ Non-drinkers } \\
\hline & & 1 & 2 & 3 & 1 & 2 & 3 \\
\hline Number & & 33 & 154 & 58 & 124 & 530 & 80 \\
\hline Proportion (per & rcentage) & 14 & 63 & 23 & 17 & 72 & 11 \\
\hline Age (years) & Mean & 28.4 & 38.5 & $46.6^{\#}$ & 31.2 & 37.1 & 48.3 \\
\hline & SD & 10.0 & 12.6 & 11.8 & 12.2 & 13.8 & 15.9 \\
\hline Alcohol intake & Mean & 12.3 & 7.7 & $20.1^{\#}$ & & & \\
\hline (g/day) & SD & 20.4 & 11.7 & 28.8 & & & \\
\hline Serum ferritin & Mean & 6 & 6.4 & $384^{\#}$ & 6 & 52 & $326^{\dagger}$ \\
\hline$(\mu \mathrm{g} / \mathrm{L})$ & SD & 3 & 3.8 & 415 & 3 & 34 & 335 \\
\hline Serum iron & Mean & 12.4 & 16.8 & $18.6^{\#}$ & 9.8 & 15.7 & $16.6^{\dagger}$ \\
\hline$(\mu \mathrm{g} / \mathrm{L})$ & SD & 8.1 & 6.9 & 8.8 & 7.1 & 7.2 & 8.5 \\
\hline Haemoglobin & Mean & 11.3 & 12.5 & $12.6^{\#}$ & 11.0 & 12.3 & $12.3^{\dagger}$ \\
\hline$(g / d L)$ & SD & 2.1 & 2.1 & 2.0 & 2.1 & 1.9 & 2.6 \\
\hline
\end{tabular}

Group 1: Serum ferritin levels below $12 \mu \mathrm{g} / \mathrm{L}$

Group 2: Serum ferritin levels between 12 and $150 \mu \mathrm{g} / \mathrm{L}$

Group 3: Serum ferritin levels above $150 \mu \mathrm{g} / \mathrm{L}$

\# Significant differences within the drinkers groups (ANOVA; $p \leq 0.001$ )

† Significant differences within the non-drinkers groups (ANOVA; $p \leq 0.001$ )

$\mathrm{SD}=$ standard deviation

and HDL-C known to be influenced by alcohol consumption ${ }^{2}$ were observed in this study, as shown in Table V.

\section{Type of alcohol consumed}

The results are not shown here, but Maclntyre ${ }^{16}$ compared the 10 food items consumed in the largest amounts per person per day across levels of urbanisation for this population. Sorghum beer was in fourth place on the food list in rural women and those living on farms; the second place in those living in informal housing areas and the eighth place in the urban middle class. No alcoholic beverage fell into the first 10 foods consumed by upper class urban women. As for men, sorghum beer was the third largest food consumed by rural men and those living on farms and in informal housing areas. Commercial beer had the second place in the urban middle class and first place in the urban upper class men.

\section{Amount of alcohol consumed}

Most European, UK and North American countries' guidelines recommend that daily alcohol intake should not exceed $5 \%$ of total energy intake, or $20 \mathrm{~g}$ for men and $15 \mathrm{~g}$ for women. ${ }^{1,6,20}$ The male drinkers in the THUSA sample reported a higher intake (a mean of $30.2 \mathrm{~g} /$ day) while the women drinkers, with a mean intake of $11.4 \mathrm{~g} /$ day, complied with this general guideline. However, the standard deviations were very large (47.8 and 18.8 respectively), illustrating a wide variety in intake with many men and women having much higher intake. Urbanisation had a small effect on amounts of alcohol consumed, but a large effect on type of alcoholic beverage taken by men, with commercial beer replacing sorghum beer in urban areas. Almost two-thirds of the men reported an intake $(61.5 \%)$ at mean levels above the recommended intake, and therefore it seems reasonable to conclude that alcohol may be a problem in the male population of this sample. In contrast, only $25 \%$ of the women reported an alcohol intake, and with mean levels generally in the recommended levels, the same conclusion cannot be drawn for women from the amounts consumed. Therefore, a closer look at biological effects of alcohol consumption is necessary.

\section{Biological effects of alcohol consumption}

The beneficial effects of moderate alcohol consumption are related to increases in HDL-C, modified platelet clotting and fibrinolytic activities $^{2,21}$ as well as a lower risk for type 2 diabetes. ${ }^{22}$ 'Moderate' refers to the recommended amounts as given in previous paragraph: less than $5 \%$ energy, or $20 \mathrm{~g}$ for men and $15 \mathrm{~g}$ for women daily. In this study platelet and fibrinolytic functions were not measured. However, fibrinogen levels did not differ between drinkers and nondrinkers and the negative correlation of fibrinogen with alcohol intake in men $(r=-0.026)$ was not significant $(p=0.513)$. The positive effect on HDL-C was significant in both male and female drinkers $(p \leq 0.005)$ but was accompanied by increased triglyceride levels in women, as shown in Table IV. Mean levels of all serum lipids were, however, within normal ranges for both men and women; the cut-off points for being normal were values $<5$ and $<1.7 \mathrm{mmol} / \mathrm{L}$ for total cholesterol and triglycerides respectively. For HDL-C, values $\geq 1$ for men and $\geq 1.2 \mathrm{mmol} / \mathrm{L}$ for women were used. ${ }^{23}$

A potential detrimental effect of alcohol intake on blood pressure disappeared when controlling for age and BMI. It seems therefore that in balance, effects of alcohol on serum lipids and blood pressure (both cardiovascular risk factors) in this sample were small. However, the effects on iron balance are of concern. Two studies, one in a rural population in Limpopo $0^{4}$ and one from Tanzania, ${ }^{5}$ interpreted the effects of alcohol on increases in serum ferritin as an improvement of iron status. The possible mechanisms offered by the authors of these papers to explain this effect are a contribution of micronutrients (including iron) by local, home-brewed beverages ${ }^{4,5}$ and an increased absorption of iron because of effects on gastric hydrochloric acid secretion and iron solubility. ${ }^{5}$

Ferritin is an iron-apoferritin complex, the major form of iron in tissue. ${ }^{18}$ It sequesters iron in a readily available form. Serum ferritin 
is proportional to intracellular ferritin and therefore under normal circumstances in equilibrium with body stores. ${ }^{18}$ Serum ferritin levels greater than $150 \mu \mathrm{g} / \mathrm{L}$ reflect stage 1 of positive iron balance. It is known that iron overload may be a problem in African adults, ${ }^{25}$ in the aged ${ }^{7,11}$ and because of excessive alcohol consumption. ${ }^{11}$ Therefore, it is necessary to evaluate and weigh a potentially positive effect of alcohol on iron status in a population known to be iron deficient ${ }^{25}$ against a possible detrimental effect on iron overload or positive iron balance.

Tables VI and VII show that if levels of serum ferritin less than $12 \mu \mathrm{g} / \mathrm{L}$ and more than $150 \mu \mathrm{g} / \mathrm{L}$ are used to classify subjects as being in either negative or positive iron balance, alcohol intake had a dramatic effect on the proportion of subjects in negative and positive balance. In men, $6 \%$ of non-drinkers and only $2 \%$ of drinkers were in negative balance. In women, the corresponding figures were 17 and $14 \%$. However, the proportion of subjects in positive balance almost doubled: from $25 \%$ in non-drinkers to $46 \%$ in drinking men and 11 to $23 \%$ in women. These changes in the proportion of subjects with increased serum ferritin levels may be interpreted as (i) that alcohol intake increased body iron stores in a substantial number of men and women, or (ii) that alcohol intake disrupted the equilibrium between the body and circulating ferritin levels.

The relationship between alcohol intake and iron status has also been examined in other populations. In an Australian study ${ }^{26}$ the effects of alcohol consumption on serum iron, transferrin and ferritin was examined in 3375 adult twin subjects. The authors concluded that "alcohol intake at low levels increases ferritin and, by inference, body iron stores". This may be either beneficial or harmful, depending on circumstances. In an American study ${ }^{27}$ adult participants of the Third National Health and Nutrition Examination Survey who did not consume alcohol $(n=8$ 839) were compared with participants who consumed $\leq 1(n=4976),>1$ to $\leq 2(n=1153)$ or $>2(n=915)$ alcoholic drinks per day during the preceding months. Compared with non-drinkers the prevalence of all markers of iron overload was significantly elevated among those who consumed more than two alcoholic drinks per day (after adjusting for potential confounders). Consumption of any amount of alcohol was associated with a $40 \%$ reduction in the risk of iron deficiency anaemia. These authors concluded that "consumption of up to 2 alcoholic drinks per day seems to be associated with a reduced risk in iron deficiency and iron deficiency anaemia without a concomitant increase in the risk of iron overload. Consumption of more than 2 alcoholic drinks per day is associated with a significant elevation in the risk of iron overload". Both these studies suggest that the effect of alcohol consumption at low levels "may be beneficial" depending on the circumstances which may be interpreted as in populations with a high prevalence of iron deficiency.

However, before there is evidence that the increased serum ferritin seen in this THUSA population as well as the Australian ${ }^{26}$ and American $^{27}$ studies on alcohol consumption is indeed reflective of increased body iron stores and not of a disputed equilibrium between body and circulating ferritin, no firm conclusion about the benefit of this effect can be drawn.

It is important that this question regarding either beneficial or harmful effects of alcohol consumption on iron status be addressed. There is an increasing global awareness of the harms associated with drinking alcoholic beverages. ${ }^{28}$ If any beneficial effects are used to motivate or justify alcohol consumption, there should be more persuasive evidence that low to moderate consumption is indeed beneficial. More research is needed before this question can be fully answered. Haemochromatosis and its genetic determinants were not measured in the THUSA population, but the above results indicate that alcohol intake may have detrimental effects on iron balance in this adult African population in transition

\section{Conclusion}

It is concluded that apparently healthy men participating in the THUSA study had a mean reported intake of alcohol that exceeded present recommendations of moderate intake, while the mean intake of women were within the upper limit of these recommendations. Subjects who were HIV infected used more alcohol than uninfected subjects. The known beneficial effects of alcohol on HDL-C were apparent, but non-drinkers also had mean HDL-C levels within the recommended range. ${ }^{23}$ Alcohol intake was associated with an increased serum ferritin level and more drinkers than non-drinkers were in positive iron balance.

\section{References}

Nutrition and Food Security Programme. WHO Regional Office for Europe. Food-based dietary guidelines in the WHO European region. Denmark: WHO; 2003.

Van Heerden IV, Parry CDH. If you drink alcohol, drink sensibly. S Afr J Clin Nutr, 2001:14(3):S71-S77.

Parry CDH. Alcohol and other drug use. In: Ntuli A, Crisp N, Clarke E, Barron P, editors. South African health review. Durban: Health Systems Trust, 2001; p. 441-454.

4. Choma SSR, Alberts M, Urdal P. Effect of traditional beer consumption on the iron status of a rural South African population. S Afr J Clin Nutr. 2007;20(2):62-68.

5. Malenganisho W, Magnussen P. Vennervald BJ, et al. Intake of alcoholic beverages is a predictor of iron status and haemoglobin in adult Tanzanians. J Nutr. 2007:137:2140-2146.

6. Walmsley CM, Bates CJ, Prentice A, Cole TJ. Relationship between alcohol and nutrient intakes and blood status indices of older people living in the UK: Further analysis of data from the National Diet and Nutrition Survey of people aged 65 years and over, 1994/5. Public Health Nutr. 1998;1(3):157-167.

Charlton KE, Kruger M, Labadarios D, Wolmarans P, Aroson I. Iron, folate and vitamin B12 status of an elderly South African population. Eur J Clin Nutr. 1997;51:424-430.

8. Milman N. Kirchhoff M. The correlation between serum ferritin, alcohol consumption and social status in a population of 2236 Danes. Ugeskr Laeger 1998;160(3):277-282

9. Ahmed F, Coyne T, Dobson A, McClintock C. Iron status among Australian adults: Findings of a population based study in Queensland, Australia. Asia Pac J Clin Nutr. 2008;17(1):40-47.

10. Valimaki M, Harkonen M, Ylikahri R. Serum ferritin and iron levels in chromic male alcoholics before and after ethanol withdrawal. Alcohol 1983:18(3):255-260.

11. Berkhan L. Interpretation of an elevated serum ferritin. Cont Med Edu. 2002;29(1):45-48.

12. Moirand R, Lescoat G, Hubert N, Dezier JF, Pasdeloup N, Brissot P. Alcohol induction of ferritin expression in a human hepatoblastoma cell line (HEP G2). Alcohol Clin Exp Res. 1990;14(6):847-852.

13. Moirand $\mathrm{R}$, Kerdavid $\mathrm{F}$, Loreal $\mathrm{O}$, et al. Regulation of ferritin expression by alcohol in a human hepatoblastoma cell line and in rat hepatocytes cultures. J Hepatology 1995;23(4):431439.

14. Robinson G, Narasimhan S, Weatherall M, Beasley R. Hemochromatosis gene mutations, liver function tests and iron status in alcohol-dependent patients admitted for detoxification. J Gastroenterol Hepatol. 2007;22(6):852-854.

15. Vorster HH, Wissing MP, Venter CS, et al. The impact of urbanisation on physical and mental health of Africans in the North-West province of South Africa: THUSA study. S Afr J Science 2000;96:505-514.

16. Maclntyre UE. Dietary intakes of Africans in transition in the North-West province. PhD dissertation, Potchefstroom, PU for CHE; 1998.

17. Langenhoven M, Kruger M, Gouws E, Faber M. Food composition tables. 3rd ed. South African Medical Research Council; 1991.

18. Kasdan TS. Medical nutrition therapy for Anaemia. In: Mahan LK, Escott- Stump S, editors. Krause's food, nutrition and diet therapy. 10th ed. London: WB Saunders, 2000; p. 781-800.

19. Vorster HH, Jerling JC, Steyn K, et al. Plasma fibrinogen of black South Africans: The BRISK study. Public Health Nutr. 1998;1(3):169-176

20. World Health Organisation. Global status report on alcohol. Geneva: WHO; 2004

21. De Groot LCP, Zock PL. Moderate alcohol intake and mortality. Nutr Rev. 1998;56(1):25-30.

22. Koppes LLJ, Bouter LM, Dekker JM, Heine RJ, Hendriks HFJ. Moderate alcohol consumption lowers the risk of type 2 diabetes. Diabetes Care 2005;28(3):719-724.

23. De Backer G, Ambrosioni E, Borch-Johnsen K, et al. Executive summary. European guidelines on cardiovascular disease prevention in clinical practice. Joint Task Force of European and other Societies on Cardiovascular Disease Prevention in Clinical Practice (constituted by representatives of eight societies and by invited experts). Eur Heart J. 2003:24:1601-1610.

24. Bothwell TH, MacPhail AP. Hereditary haemochromatosis: Etiologic, pathologic and clinical aspects. Semin Hematol. 1998:35:55-71.

25. Kruger HS, Kruger A, Vorster HH, Jooste PL, Wolmaraus P. Urbanisation of Africans in the North West province is associated with better micronutrient status: The Transition and Health during Urbanisation Study in South Africa. Nutr Res 2005;25:365-375.

26. Whitfield JB, Zhu G, Heath AC, Powell LW, Martin NG. Effects of alcohol consumption on indices of iron stores and of iron stores on alcohol intake markers. Alcohol Clin Exp Res. 2001:25(7):1037-1045.

27. Ioannou GN, Dominitz JA, Weiss NS, Heagerty PJ, Kowdley KV. The effect of alcohol consumption on the prevalence of iron overload, iron deficiency, and iron deficiency anaemia. Gastroenterology 2004;126(5):1293-1301

28. Grimm D. Staggering toward a global strategy on alcohol abuse. Science 2008;320(5878):862-863. 